\title{
$\equiv Q$
}

\section{EUROPEAN RESPIRATORY journal}

FLAGSHIP SCIENTIFIC JOURNAL OF ERS

\section{Sniff test: does what we measure at the nose reflect what happens in the chest wall?}

Antonella LoMauro, Cristina Martorana, Andrea Aliverti, Mario Nosotti, Alessandro Palleschi, Emilia Privitera

European Respiratory Journal 2019 54: PA2194; DOI: 10.1183/13993003.congress-2019.PA2194

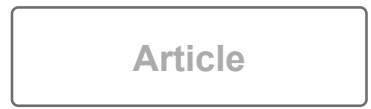

Figures \& Data

Info \& Metrics

\begin{abstract}
Nasal pressure measured during sniff (SNIP) is a technically simple voluntary test. Since the contraction of the diaphragm expands the abdomen, the volume variation during sniff manoeuvre should therefore be predominantly abdominal in order to be considered a specific index of diaphragm strength.
\end{abstract}

We aimed to verify if and how SNIP varied according to thoraco-abdominal volume variations.

We measured abdominal volume variations, using opto-electronic plethysmography, during quiet breathing $\left(\mathrm{AB}_{\mathrm{QB}}\right)$ and sniff manoeuvres $\left(\mathrm{AB}_{\mathrm{SN}}\right)$ in supine position on 30 patients (age: 42; FVC:47.5\%; $F E V_{1}: 30 \%$ ) on the waiting list for lung transplant. SNIP was measured simultaneously with $\mathrm{AB}_{\mathrm{SN}}$. 68 sniff were analysed and classified into 4 groups according to $\mathrm{AB}_{\mathrm{SN}}$ : 16 with thoracic paradox, 24 predominantly abdominal, 16 predominantly thoracic and 12 with abdominal paradox.

By definition $\mathrm{AB}_{\mathrm{SN}}$ was different $(\mathrm{p}<0.001)$ among the 4 groups, whereas $\mathrm{AB}_{\mathrm{QB}}(\sim 75 \% ; \mathrm{p}=0.373)$ and SNIP $(\sim 53$ $\mathrm{cmH}_{2} \mathrm{O}, \mathrm{p}=0.792$ ) were similar (figure 1).

SNIP did not change with the different thoraco-abdominal strategies. The diaphragm was not weak and leaded inspiration, therefore $A B_{S N}$ varied because the patients misperformed the manoeuvre.

In order to not misunderstand the clinical significance of a sniff test, care should be paid also in thoracoabdominal movement because SNIP, per se, cannot differentiate between thoracic or diaphragmatic manoeuvre with the risk to lose its specificity. 

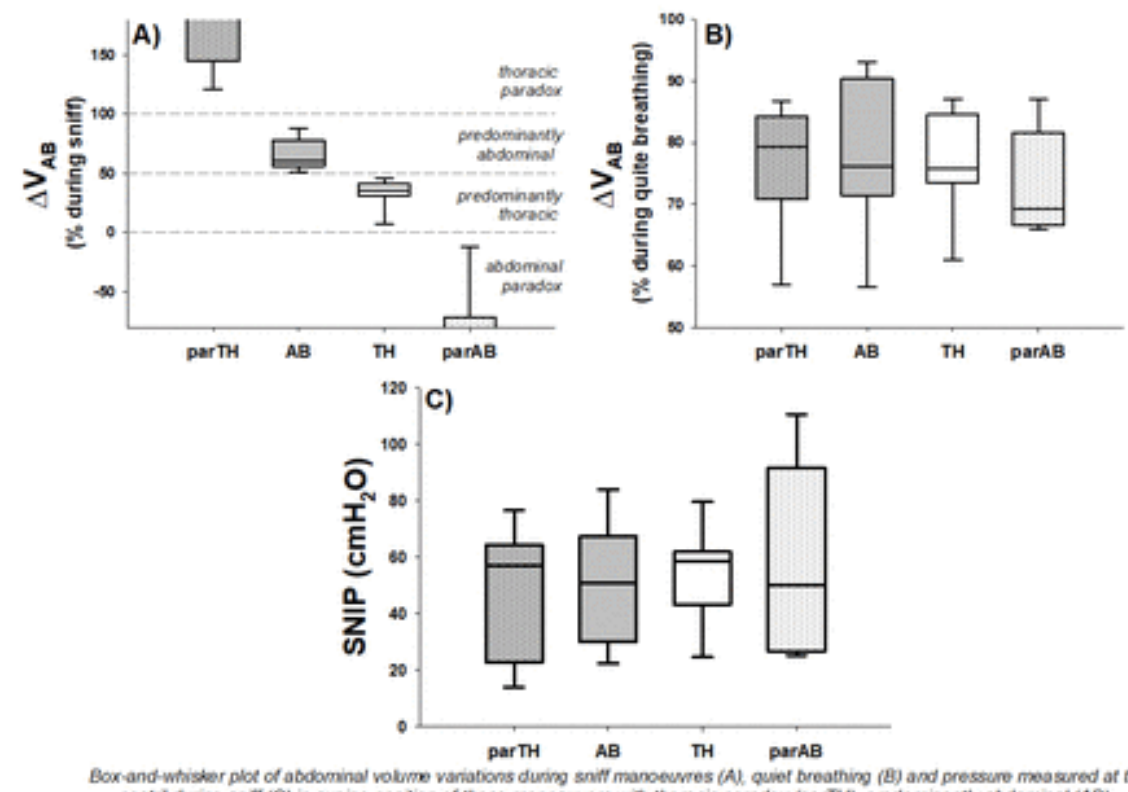

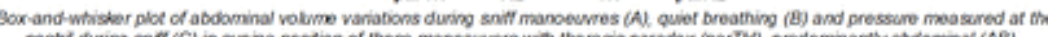

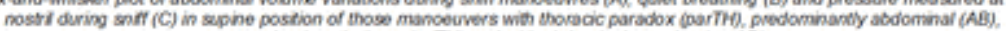
predominumbly froracic (Th) and with abdomind paradox (pashB)

Download figure

Open in new tab

Download powerpoint

Respiratory muscle Critically ill patients Spirometry

\section{Footnotes}

Cite this article as: European Respiratory Journal 2019; 54: Suppl. 63, PA2194.

This is an ERS International Congress abstract. No full-text version is available. Further material to accompany this abstract may be available at www.ers-education.org (ERS member access only).

Copyright @the authors 2019

\section{We recommend}

Respiratory muscle activation and action during cough

Antonella LoMauro et al., European Respiratory Journal, 2013

Influence of different factors in maximal nasal inspiratory pressure (SNIP) values in healthy volunteers
Respiratory thoraco-abdominal mechanics in man Joseph Milic-Emili et al., Journal of Applied Physiology, 1964

P233 Structured light plethysmography correlates well with inspiratory muscle strength in pompe disease SC Madathil et al., Thorax, 2018 
Ana Balañá et al., European Respiratory Journal, 2013

Measuring inspiratory muscle strength in neuromuscular disease: one test or two?

N Terzi et al., European Respiratory Journal, 2007

Sniff nasal inspiratory pressure in children with muscular, chest wall or lung disease.

B Fauroux et al., European Respiratory Journal, 2008

Can sniff nasal pressure (SNIP) measurement be used interchangably or complementary to maximum inspiratory pressure (MIP) to ankylosing spondylitis

(AS) patients?

Charalampos Mandros et al., European Respiratory

Journal, 2013
C0091 Dynamic transabdominal ultrasound: assessing the reduction of the pelvic floor displacement during the cough

Beatriz Navarro Brazález et al., British Journal of Sports Medicine, 2018

Diaphragmatic dysfunction and respiratory illness (Review)

PulmCCM, PulmCCM

Q\&A: Biden Cancer Initiative President Greg Simon Discusses Data Sharing in Precision Oncology

Precision Oncology News, 2019

\section{Powered by TREND MD}

I consent to the use of Google Analytics and related cookies across the TrendMD network (widget, website, blog). Learn more

$\boldsymbol{\theta}$ Previous

Back to top

Vol 54 Issue suppl 63 Table of Contents

Table of Contents

Index by author

Email

$\checkmark$ Alerts

Citation Tools
(C) Request Permissions

Share
Jump To
Article
- Figures \& Data
Info \& Metrics 
More in this TOC Section

\section{Lelated Articles}


No related articles found.

\section{Navigate}

Home

Current issue

Archive

\section{About the ERJ}

Journal information

Editorial board

Reviewers

CME

Press

Permissions and reprints

Advertising

\section{The European Respiratory Society}

Society home

myERS

Privacy policy

Accessibility

\section{ERS publications}

European Respiratory Journal

ERJ Open Research

European Respiratory Review

Breathe

ERS books online

ERS Bookshop

\section{Help}

Feedback

\section{For authors}

Instructions for authors

Submit a manuscript

ERS author centre

\section{For readers}

\section{Alerts}


Subjects

Collections

Podcasts

RSS

Subscriptions

Accessing the ERS publications

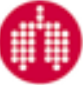

\section{Contact us}

European Respiratory Society

442 Glossop Road

Sheffield S10 2PX

United Kingdom

Tel: +44 1142672860

Email: journals@ersnet.org

\section{ISSN}

Print ISSN: 0903-1936

Online ISSN: 1399-3003

Copyright (C) 2019 by the European Respiratory Society 